\title{
A TECHNIQUE FOR DETECTING Treponema pallidum THROUGH THE USE OF MEMBRANE FILTERS AND IMMUNOFLUORESCENCE STAINING* $†$
}

\author{
BY \\ FRANCIS W. CHANDLER, Jr. \\ Venereal Disease Research Laboratory, Venereal Disease Branch, \\ State and Community Services Division, \\ National Communicable Disease Center, \\ Health Services and Mental Health Administration, \\ Public Health Service, \\ U.S. Department of Health, Education, and Welfare, \\ Atlanta, Georgia 30333, U.S.A.
}

Danielsson (1965) has recently described the use of non-fluorescent membrane filters and immunofluorescence staining for the identification of certain bacteria in water. The principal advantages of the procedure were that it was rapid; that it could separate and identify a small number of organisms from a relatively large volume of fluid; and that it allowed a quantitative estimate of the concentration of organisms in the fluid.

Recent reports of spiral organisms in the aqueous humour and cerebrospinal fluid of syphilitics (Girard, Goldman, Baumstark, and Stickle, 1967; Goldman and Girard, 1967, 1968; Smith and Israel, 1967a, 1967b, 1968) have stimulated our interest in constructing and calibrating immunofluorescence procedures which may be useful in the detection of such organisms (Chandler and Cannefax 1969); (Chandler and Norins, 1969). We report here the detection of Treponema pallidum by the use of membrane filters and immunofluorescence staining.

\section{Material and Methods}

Source of Test Organisms A lyophilized antigen ( $T$. pallidum, Nichols strain), as described for use in the Fluorescent Treponemal Antibody-Absorption (FTAABS) test (Staff, Venereal Disease Research Laboratory, 1969), was selected as the test material and was subsequently reconstituted with $1 \mathrm{ml}$. distilled water to the original volume. The $T$. pallidum suspension was well mixed to ensure an even distribution of organisms and then examined by darkfield microscopy to confirm adequate dispersion. It was further determined, by darkfield examination, that the $T$. pallidum suspension

* Received for publication May 12, 1969.

†Trade names are used for identification only and do not represent an endorsement by the Public Health Service or the U.S Department of Health, Education, and Welfare. contained approximately forty organisms per $440 \times$ high dry microscopic field (hdf). The 1-ml. reconstituted stock suspension was diluted using distilled water to give a final $T$. pallidum concentration of one organism/ hdf. This concentration of treponemes was used as the stock suspension for serial dilution, filtration, staining, and evaluation. The relation of the number of organisms/hdf to the number $/ \mathrm{ml}$. was determined by the method of Morgan and Vryonis (1938), as described previously (Chandler and Cannefax, 1969).

Filtration Four ten-fold dilutions of the $T$. pallidum stock suspension were made by using an initial $0 \cdot 1 \mathrm{ml}$. treponemal suspension containing approximately 36,600 organisms. Using a disposable pipette and rubber bulb, each dilution was then well mixed to ensure an even distribution of organisms. A $0 \cdot 1-\mathrm{ml}$. sample taken separately from each of the four dilutions and from the stock suspension was aspirated into a 1-ml. tuberculin syringe. The syringe was fitted to a Swinnex-13 filter assembly containing a $13-\mathrm{mm}$. black non-fluorescent Millipore filter (GSBP01300), pore size $0.22 \mu . \star$ Before the filter was seated in the filter assembly it was floated in a container of phosphate-buffered saline (PBS) for $5 \mathrm{~min}$. at $40^{\circ} \mathrm{C}$. The $0 \cdot 1 \mathrm{ml}$. T. pallidum suspension was then forced into the filter assembly in a matter of seconds by pressure on the syringe plunger. The syringe was detached immediately, filled with $0.3 \mathrm{ml}$. PBS, reattached to the filter assembly, and used to force the PBS through the non-fluorescent filter. This refilling and flushing was done twice to give the maximum chance for recovery of any stray treponemes.

Immunofluorescence Staining After filtration, the Swinnex assembly was disengaged, holding the upper half upright. The upper half with rubber gasket was inverted and closed at the outlet by placing it upright in a clay holder. It was then filled up to the gasket with PBS. Using forceps with unserrated tips, the filter was carefully removed from the lower assembly half and

^Millipore Corporation, Bedford, Mass. 01730. 
placed on the rubber gasket. The filter was then ready for staining.

The organisms trapped on the filter surface were stained by a direct fluorescent antibody procedure (Venereal Disease Research Laboratory, 1967a) using fluorescein-conjugated rabbit anti- $T$. pallidum globulin (Venereal Disease Research Laboratory, 1967b) produced by Mrs. Susan Mothershed in this laboratory (Lot No. 712227R2). By trial and error, it was determined that for this membrane filtration method, the best results were obtained by using the conjugate undiluted. Approximately $0.03 \mathrm{ml}$. undiluted conjugate was placed on the filter surface and allowed to incubate for 1 hour in a humid chamber at room temperature. After incubation, the assembly was removed from the clay, thus opening the outlet to allow for drainage. Using forceps, the filter was transferred to a container of PBS and "floated" for $3 \mathrm{~min}$. to remove excess conjugate. It was then mounted on a glass microscope slide for fluorescence microscopy. This filtration and staining procedure was repeated on five samples of each dilution, and on Reiter treponemes as a negative control.

Fluorescence Microscopy A Leitz Ortholux ${ }^{\star}$ fluorescence microscope equipped for incident ultraviolet illumination with a $50 \times$ Ultropak ${ }^{\star}$ dry objective lens was used for filter examinations.

For the lower dilutions of the stock solution, the number of $T$. pallidum organisms observed on the filter surface was calculated using the equation reported by Danielsson (1965) as follows:

$$
x=\frac{N \times R^{2}}{20 \times r^{2}}
$$

where $N=$ number of treponemes in 20 fields of vision, $R=$ diameter of the filtering surface $(9.4 \mathrm{~mm}$.), and $r=$ diameter of the field of vision $(0.31 \mathrm{~mm}$.).

For higher dilutions of the stock solution, the entire filtering surface $\left(0.7 \mathrm{~cm} .{ }^{2}\right)$ was examined in a systematic manner before a specimen was regarded as negative.

\section{Results and Comment}

Our findings are summarized in the Table. When there were more than 36 organisms $/ 0.1 \mathrm{ml}$., exam-

TABLE

RECOVERY OF TREPONEMA PALLIDUM BY MEMBRANE FILTRATION FOLLOWED BY IMMUNOFLUORESCENCE STAINING

\begin{tabular}{c|c|c|c}
\hline $\begin{array}{c}\text { Approximate } \\
\text { Number of } \\
\begin{array}{c}\text { Treponemes } \\
\text { Filtered }\end{array} \\
\begin{array}{c}\text { (each in volume } \\
\text { of 0.1 ml.) }\end{array}\end{array}$ & $\begin{array}{c}\text { Number of } \\
\text { Treponemes } \\
\text { Detected } \\
\text { (average of 5 } \\
\text { determina- } \\
\text { tions) }\end{array}$ & $\begin{array}{c}\text { Calculated } \\
\text { Total Number } \\
\text { of Treponemes } \\
\text { Recovered } \\
\text { (see text } \\
\text { for formula) }\end{array}$ & $\begin{array}{c}\text { Approximate } \\
\text { Percentage } \\
\text { Recovery }\end{array}$ \\
\hline $36,600.00$ & $738 / 20$ fields & $33,928.0$ & 92.7 \\
$3,660.00$ & $72 / 20$ fields \\
366.00 & $6 / 20$ fields & $3,310.0$ & 90.4 \\
36.60 & $23 /$ entire filter & 276.0 & 75.4 \\
3.66 & $0.6 /$ entire filter & 23.0 & 62.8 \\
\hline
\end{tabular}

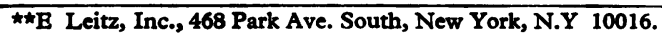

ination of the filter proceeded rapidly; it required approximately $75 \mathrm{~min}$. completely to filter, stain, and read one of the suspensions. When there were only 3.6 organisms $/ 0.1 \mathrm{ml}$., examination of the filter was prolonged and tedious, and in five samples the number of organisms found was $0,0,2,1,0$. Reiter treponemes were trapped on the filter but did not stain. The filtrates were examined by darkfield microscopy to determine if any appreciable number of treponemes had passed through, but no organisms were seen. The stained $T$. pallidum organisms on the filter surface showed a uniform affinity for the fluorescent antibody conjugate, and they also showed the usual morphology. The fluorescence intensity was of $2+$ to $3+$ magnitude, considering $4+$ as the maximum obtained with direct fluorescent antibody staining of $T$. pallidum fixed to glass microscope slides and observed with transmitted untraviolet light. It is apparent that this procedure offers a means for the detection of $T$. pallidum, and several clinical and research applications are being explored.

\section{Summary}

The detection of $T$. pallidum in fluids by the use of non-fluorescent membrane filters and immunofluorescence staining was developed and evaluated. Organisms trapped on the filtering surface were stained using fluorescein-conjugated rabbit anti- $T$. pallidum globulin and, when examined by incident ultraviolet illumination, they showed typical morphology with a uniform affinity for the conjugate. Examination of the filtering surface proceeded rapidly when there were more than 36 organisms/ $0.1 \mathrm{ml}$., but detection of organisms proved to be a prolonged and tedious procedure when only 3.6 organisms $/ 0.1 \mathrm{ml}$. were filtered and examined.

The author wishes to thank Dr. U. S. G. Kuhn, III, Dr. L. C. Norins, and Mrs. Susan M. Mothershed for their interest and encouragement.

\section{REFERENCES}

Chandler, F. W., Jr., and Cannefax, G. R. (1969). Brit. F. vener. Dis., 45, 1.

- and NorINs, L. C. (1969). Ibid., 45, 117.

Danielsson, D. (1965). Acta path. microbiol. scand., 63, 597.

Girard, K. F., Goldman, J. N., Baumstark, J. S., and STICKLE, D. W. (1967). "Observations on Late Congenital Syphilis with Ocular Disease: Laboratory Aspects". Presented at the 95th Annual Meeting of the American Public Health Association, Laboratory Section, Miami Beach, Florida, Oct. 24, 1967.

Goldman, J. N., and GIRARD, K. F. (1967). Arch. Ophthal. (Chicago), 78, 47.

\section{—— (1968). Ibid., 79, 716.}


Morgan, H. J., and Vryonis, G. P. (1938). Amcr. F. Syph., 22, 462.

Smith, J. L., and IsRael, C. W. (1967a). Arch. Ophthal. (Chicago), 77, 474.

(1967b). F. Amer. med. Ass., 199, 980. (1968). Trans. Amer. Acad. Ophthal. Otolaryng., 72, 63.

Venereal Disease Research Laboratory (1967a). "Provisional Technique for the Direct Immunofluorescent Identification of Treponema pallidum in Body Fluids and Tissue Sections in Current Use at the Venereal Disease Research Laboratory", June 15, 1967. Venereal Disease Research Laboratory, National Communicable Disease Center, Atlanta, Georgia 30333.

(1967b). "Properties and Instructions for Use of Lyophilized Fluorescein-Conjugated Anti- $T$. pallidum Globulin (Rabbit Origin)". Idem.

(1969). "Manual of Tests for Syphilis". P.H.S.
Publication No. 411 (revised Jan., 1969). U.S. Government Printing Office, Washington, D.C.

Une technique de recherche du Treponema pallidum utilisant une membrane filtrante et le marquage par immunofluorescence.

\section{SOMMAIRE}

On expose et évalue une méthode de détection du $T$. pallidum dans les milieux liquides qui utilise des membranes filtrantes non fluorescentes et le marquage immunofluorescent. Les organismes retenus sur la surface du filtre furent colorés par la globuline de lapin anti- $T$. pallidum conjuguée à la fluoresceine et, ceux-ci, sous excitation ultra-violette, montrèrent une morphologie typique avec une affinité uniforme pour le conjugué. L'examen de la surface filtrante s'effectue rapidement lorsqu'il y a plus de 36 organismes $/ 0,1 \mathrm{ml}$., mais la détection des organismes devient un procédé long et fatigant lorsque la concentration filtrée et examinée est seulement de 3,6 organismes $/ 0,1 \mathrm{ml}$. 